\title{
PSYCHOLOGICA
}

\section{Busca e cura de sentido para a vida}

Autor(es): $\quad$ Barros-Oliveira, José $\mathrm{H}$.

Publicado por: Imprensa da Universidade de Coimbra

URL

persistente:

URI:http://hdl.handle.net/10316.2/5466

DOI: $\quad$ DOI:http://dx.doi.org/10.14195/1647-8606_51_7

Accessed : $\quad$ 26-Apr-2023 10:45:00

A navegação consulta e descarregamento dos títulos inseridos nas Bibliotecas Digitais UC Digitalis, UC Pombalina e UC Impactum, pressupõem a aceitação plena e sem reservas dos Termos e Condições de Uso destas Bibliotecas Digitais, disponíveis em https://digitalis.uc.pt/pt-pt/termos.

Conforme exposto nos referidos Termos e Condições de Uso, o descarregamento de títulos de acesso restrito requer uma licença válida de autorização devendo o utilizador aceder ao(s) documento(s) a partir de um endereço de IP da instituição detentora da supramencionada licença.

Ao utilizador é apenas permitido o descarregamento para uso pessoal, pelo que o emprego do(s) título(s) descarregado(s) para outro fim, designadamente comercial, carece de autorização do respetivo autor ou editor da obra.

Na medida em que todas as obras da UC Digitalis se encontram protegidas pelo Código do Direito de Autor e Direitos Conexos e demais legislação aplicável, toda a cópia, parcial ou total, deste documento, nos casos em que é legalmente admitida, deverá conter ou fazer-se acompanhar por este aviso. 
NÚMERO 51

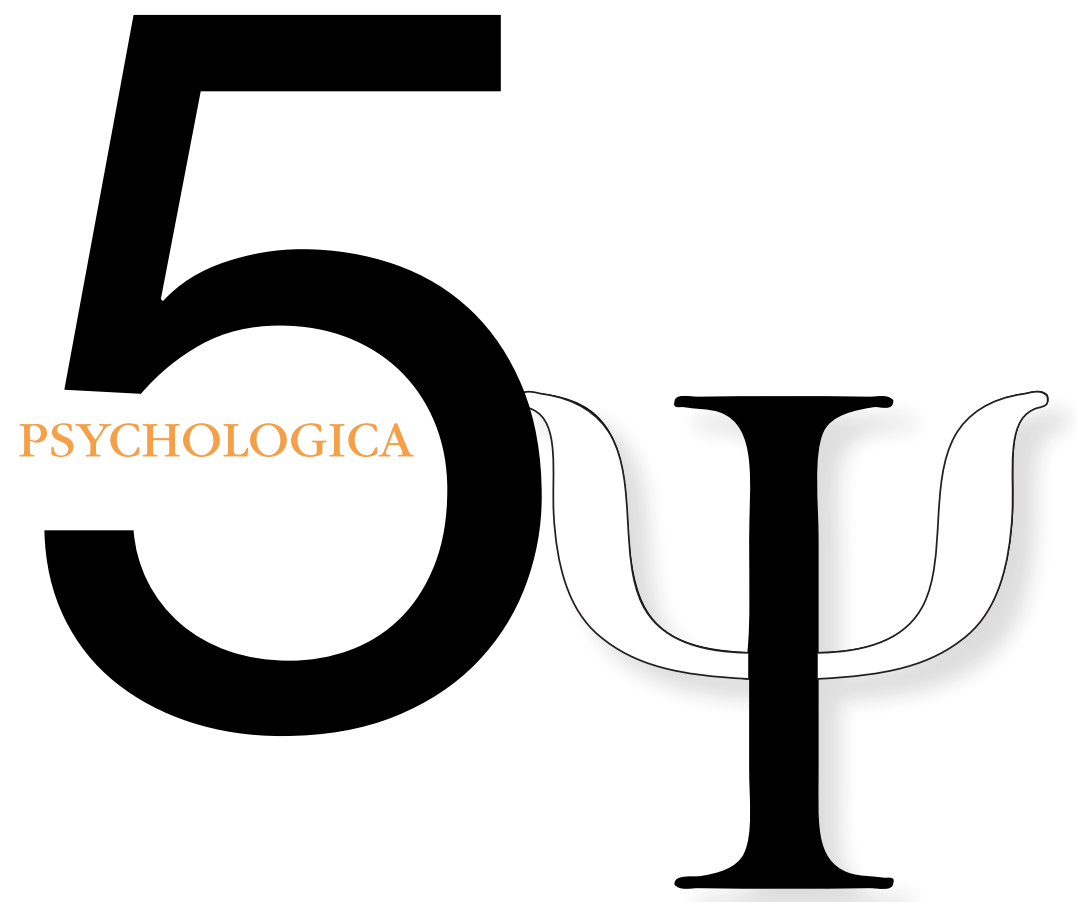

IMPRENSA DA UNIVERSIDADE DE COIMBRA

FACULDADE DE PSICOLOGIA E DE CIÊNCIAS DA EDUCAÇÃO DA UNIVERSIDADE DE COIMBRA 


\title{
Busca e cura de sentido para a vida
}

José H. Barros-Oliveira'

\begin{abstract}
A busca de sentido para a vida, ou de uma vida com sentido, é hoje tão ou mais premente do que no tempo de V. Frankl que estudou particularmente este tópico ou esta dimensão psico-espiritual. $\mathrm{O}$ autor constata não apenas a falta de sentido existencial, mas procura uma terapia adequada - logoterapia. Depois de breve introdução, estuda-se a vontade de significado que é própria do homem racional e depois a tentativa de cura da falta de sentido, que de algum modo torna a psicologia, e em particular a psicoterapia, mais 'humana'.
\end{abstract}

PALAVRAS-CHAVE: busca de sentido; vontade de significado; logoterapia; psicologia.

O ser humano não busca a felicidade; procura uma razão de ser feliz (V. Frankl). Importante não é o que esperamos da vida, mas o que damos à vida (V. Frankl). Que valor tem a vida se não é para ser dada? (Paul Claudel). A única arte digna desse nome é a arte de ensinar o verdadeiro sentido da vida a quem não o possui (Eurípedes). Tornar a vida suportável é o primeiro dever do ser vivo (Freud).

Busco um porto, uma nau desconhecida l e esse é todo o sentido da minha vida (F. Pessoa).

Trata-se de um tópico menos versado pelos psicólogos, mas que se enquadra no âmbito da Psicologia Positiva (Barros, 2004), a par de outros temas, como o amor, a esperança, o optimismo, a sabedoria, o perdão, a felicidade, etc., na confluência com a filosofia e a religião, pois cada teoria filosófica e sobretudo cada religião apresenta um projecto de vida e de felicidade, embora haja muitas propostas 'em segunda mão', com interesses económicos, vendendo 'banha da cobra', apresentando, concretamente, um sentido para a vida muito relativo e à la carte que deixa na boca um sabor amargo e a desilusão (Terra, 2009).

1 Faculdade de Psicologia e de C. E., Universidade do Porto. 
Neste momento interessa-nos particularmente uma pespectiva psicológica do sentido da vida, embora de tendência fenomenológica e existencial, até porque a psicologia experimental e comportamental passou ao lado desta problemática. A busca de sentido abrange uma dimensão cognitivo-afectivo-motivacional, podendo considerar-se uma atitude existencial, meta do processo de crescimento espiritual do homem. Só buscando (e encontando) um significado duradouro para a vida, a pessoa humana pode ser minimamente feliz.

Tal sentido é irmão da Esperança. Efectivamente, Kant (1966, p. 25), na introdução à Lógica, diz que a filosofia visa fundamentalmente responder a quatro perguntas: "Que posso fazer? Que devo fazer? Que me é permitido esperar? O que é o homem?". Saber e poder esperar constitui já uma resposta sobre o homem, que poderíamos definir como "um ser de esperança" ou "um ser para a esperança”. Só que há esperanças com minúscula e Esperança com maiúscula, feita de esforço confiante e perseverante e aberta à transcendência. Só esta Esperança, capaz de suportar as incertezas e ultrapassar o desepero, evita a ilusão e consequente desilusão e pode dar equilíbrio, maturidade e felicidader ao ser humano (cf. Barros, 2004; Brito, 2009).

A psicologia aborda o tema do sentido sob diversas perspectivas. Antes de mais, poderíamos aproximar este construto do que Gardner (1999), autor das "Inteligências múltiplas", chama "inteligência existencial" (capacidade para compreender o sentido da vida e da morte, o destino do mundo e das pessoas, e ainda capacidade de amar e de se extasiar diante da beleza), e ainda "inteligência espiritual" (capacidade de interpretar a existência desde diversas perspectivas, incluindo a transcendente e religiosa) (cf. Antunes, 2005).

Para Zica e Chamberlain $(1987,1992)$ ter sentido na vida é um forte preditor do bem-estar psicológico. Ter significado na vida é perseguir objectivos de valor, sentindo ao mesmo tempo uma vida em plenitude (cf. Reker e Wong, 1988). Seifert (2002) estuda a busca de sentido em relação com a religião e a espiritualidade, tendo em conta sobretudo a terceira idade (cf. Brody, 1999). Yalom (1980) faz uma sintese sobre os autores que se dedicaram a este construto, aplicando à terapia existencial. Outros estudos centram-se na relação entre o significado na vida e a saúde mental, com referências à depressão, ao uso de estupefacientes e outras tendências patológicas, fruto muitas vezes de uma vida sem sentido (cf. Newcomb, 1986). Maddi (1967) estuda a neurose existencial devido à falta de sentido em que as pessoas vivem. Há pesquisas centradas na psicoterapia, confrontando o budismo, o desenvolvimento espiritual, a psicoterapia existencial e a logoterapia de Frankl (O'Neill, 2001). Outras pesquisas, no âmbito da saúde, com preocupações psicoterapêuticas, relacionam a busca de sentido com a Sida (Carlisle, 2000) ou com o cancro (Ersek e Ferrell, 1994). 


\section{Vontade de sentido}

Na sequência de outros autores, sobretudo dos filósofos existencialistas, Jung (1933), já no campo da psicologia, e mais concretamente da psicanálise, tinha-se preocupado em procurar e encontrar sentido para a vida ou uma vida com sentido. Todavia, foi Victor Frankl $(1998,2001)$, um psiquiatra de Viena, radicado nos Estados Unidos, quem mais estudou o search for meaning, talvez por ter vivido três anos no campo de concentração de Auschwitz (ele era de origem judaica), onde pereceram todos os seus familiares; apesar de tudo não perdeu o sentido da vida, embora de algum modo quase se sentisse culpado de sair daquele inferno com vida. Com essa trágica lição da história (geral e pessoal) procurou novos caminhos e razões de viver, derivando dessa busca de sentido a consequente psicoterapia - 'logoterapia' (o vocábulo grego logos significa 'razão, 'palavra', 'sentido') - tentativa de curar as diversas neuroses (ansiógenas) dando sentido ou razões de viver.

Convencendo-se de que mesmo em circunstâncias absolutamente trágicas, em situações-limite entre a vida e a morte, não se deve perder o sentido Assim, considera como neurose não apenas as perturbações radicadas na esfera psicológica mas também as provocadas por problemas espirituais ou existenciais. Neste sentido, a logoterapia surge como uma "re-humanização da psicoterapia" que deve contar também com a capacidade de autodistanciamento e de autotranscendência da pessoa humana.

No discurso inaugural, no $3^{\circ}$ Congresso Internacional de Logoterapia (Universidade de Regensburg, Junho 1983), Frankl (1998) intitulou a sua intervenção: "argumentos para um optimismo trágico". A logoterapia é concebida como uma psicoterapia centrada no sentido da vida. O homem é um ser em constante busca de sentido para a vida; porém, no mundo actual cada vez mais se sente frustrado por não encontrar esse sentido, e por isso é vítima da "tríade trágica": sofrimento, culpa, morte (p. 13).

Apesar de tudo, é possível dizer sim à vida? Pode a vida ter um sentido e conservá-lo para além de tantos aspectos negativos? Sim, é necessário olhar a vida tal como ela é, é necessário dar sentido aos aspectos negativos, isto é, “transformar o sofrimento em prestação, a culpa em transformação, a morte num incentivo a agir responsavelmente" (p. 14). Temos de aprender isso com modelos verdadeiramente significativos do homo patiens (para um cristão, o protótipo deste 'homem sofredor' é Jesus Cristo).

Urge encontrar um sentido geral para a vida, um sentido último, mas também um sentido concreto para situações concretas, como o sofrimento, o luto ou a própria morte. A nova geração intitula-se a si mesma no future generation; assim sendo, nada a esperar, senão a droga, a depressão, o suicídio, a violência. Efectivamente, propaga-se hoje cada vez mais "a síndroma do sem-sentido" (p. 19). Para ultra- 
passar tal síndroma, V. Frankl inspira-se nos filósofos existencialistas e de modo particular na antropologia fenomenológica de Max Scheler que realça o valor do espírito no homem (Já S. Paulo distinguia entre corpo (sôma), mente (psichê) e espírito (pneuma) - 1 Tes 5,23).

96 Na dialéctica entre espírito e instinto, entre liberdade e condicionamento, deve prevalecer o espírito capaz de libertar a pessoa humana para altos voos. Assim como o corpo e a psiquê podem adoecer, também o espírito muitas vezes enferma e a sua doença é a falta de sentido ou de significado último para a vida. A psicoterapia procura 'curá-lo' desta falta de sentido, motivando nele a "vontade de sentido" que leva à vontade de viver e de amar, dedicando-se realmente a valores nobres e essenciais e menosprezando o secundário e efémero. Tudo isto muito para além da "vontade de prazer" (Freud) ou da "vontade de poder" (Adler).

No nosso tempo assiste-se a uma grande contradição, particularmente nos países mais desenvolvidos: tem-se tudo e ao mesmo tempo não se tem nada, porque não se é feliz. Reina o absurdo, o vazio ("A era do vazio" - é o título de um livro de Lipovetsky, 1988, devido em grande parte ao "império do efémero", outro título sugestivo de Lipovetsky, 1989), instalou-se o niilismo, a frustração existencial, o suicídio imediato ou lento, através da depressão. São frutos de um "homem light" (Rojas, 1988) ou de "uma vida sem valores", que este psiquiatra espanhol usa como subtítulo do seu livro. Nesta contingência, é cada vez mais urgente a busca de significado, de valores autênticos, de verdadeiras razões de viver. É neste contexto que ganha mais actualidade a teoria de Frankl, na sequência da melhor psicologia humanista ou fenomenológica.

A psicanálise de Freud está voltada para o passado e os seus traumatismos (sexuais); a logoterapia olha para o futuro, procurando dar lugar à esperança na busca constante de um sentido para a vida. Freud realça a frustração na vida sexual e a suas implicações neuróticas; Frankl estuda a frustração provinda do não-sentido da vida. O homem não é apenas busca de prazer, de bens materiais ou de sucesso e poder, mas sobretudo anelo de infinito, de transcendência. Como consequência, as neuroses não provêm propriamente de frustrações sexuais mas de frustrações existenciais ou de falta de sentido. Mesmo a busca a todo o custo de prazer, que passa pelo sexo, pela droga, pelo álcool, etc., no fundo é busca desesperada de sentido, vontade de significado, busca de razões autênticas de viver. O homem sente-se vazio e procura encher-se de coisas e de prazeres efémeros que não alimentam a longo prazo o espírito, deixando-o ainda mais sofrido.

Não obstante, a logoterapia não tem propriamente finalidades éticas ou religiosas. Podemos dizer, com Frankl (2001, p. 69), que "o fim da psicoterapia é a cura psíquica, enquanto o fim da religião é a salvação da alma”, embora as duas realidades se possam dar as mãos e convergir para a realização da pessoa nesta 
vida e na eternidade, pois a pessoa tende não apenas à "auto-realização" que também à "auto-transcendência". Nem a logoterapia nem a religião evitam o sofrimento mas dão-Ihe sentido, mesmo à própria morte, ou ao menos evitam cair no desalento ou no desespero. Assim sendo, em certo sentido pode considerar-se a logoterapia como apelando à religião uma vez que já o próprio Einstein, citado por Frankl (2001, p. 116), afirma que interrogar-se sobre o significado da vida já significa de algum modo ser religioso.

\section{Logoterapia e re-humanização da psicologia}

No seu livro "A vontade de significado" (a edição italiana intitulou "Sentido e valores para a existência", 1998) que reflecte uma série de conferências dadas em 1966 no Texas (USA), V. Frankl faz uma boa síntese sobre a sua teoria e prática psicoterapêutica. No Prefácio afirma que a logoterapia tem o seu fundamento em três conceitos: liberdade da vontade, vontade de significado (para além da vontade de poder, inspirada em Nietzsche e Adler, e vontade de prazer, de inspiração freudiana) e significado da vida. É nesta que o autor insiste particularmente, pois a logoterapia ensina a dar significado mesmo aos aspectos trágicos e negativos da existência pondo-os ao serviço do crescimento pessoal.

A logoterapia, ao contrário de algumas correntes existencialistas, não é pessimista, mas realista e mesmo optimista. Pretende levar o paciente a olhar de frente a "trágica tríade da existência humana: dor, culpa, morte" (p. 17). Frankl insiste em conceitos fundamentais como o desejo de transcendência ínsito em cada ser humano e que o aproxima da dimensão religiosa. O "vazio existencial", a "frustração existencial", o aborrecimento e a apatia que levam à "neurose noogénica" só podem ser ultrapassados dando significado e transcendência à vida. E a espiritualidade e/ou religião compensa de algum modo o horror e ajuda a superá-lo, conforme o dito conhecido de V. Frankl (1999, 183): "O homem inventou as câmaras de gaz em Auschwitz, mas foi ele também que lá entrou, cabeça erguida e o Pai Nosso ou o Shema Israel nos lábios".

Como afirma Fizzonni, um especialista de Frankl, na apresentação da "Vontade de significado" (1998), devemos dar mais peso à reflexão (que tem a ver com a busca de significado existencial) e não apenas à acção ou produção, como já tinha notado Heidegger. Por sua vez Jaspers, outro filósofo existencialista, chamou "superstição" do nosso tempo à idolatria da ciência e da técnica que sonhou ser capaz de fazer o homem feliz e de resolver todos os problemas, quando na realidade há cada vez mais frustração e infelicidade. Urge encontrar significado e solução para os problemas existenciais para além da intramundanidade, abrindo-se à transcendência e, 
no fim de contas, a Deus, a quem Frankl chamava o “Personalíssimo”. É necessário procurar a convergência entre as diversas ciências humanas, em particular a(s) psicologia(s), e a religião e/ou espiritualidade (cf. Barros, 2006).

Continua a publicar-se bibliografia sobre os diversos aspectos da obra de Frankl e 98 em particular sobre a logoterapia, desde perspectivas diferenciadas, como o artigo de Schulenberg et al. (2008) que se centra particularmente na prática clínica. Os autores discutem os princípios fundamentais deste método psicoterapêutico, a sua aplicabilidade e técnicas e ainda o papel do terapeuta e alguns instrumentos de avaliação. Outros artigos são mais específicos, como o de Jim et al. (2006) que estudam em particular as estratégias usadas pelas pessoas que se confrontam com o cancro, havendo muitas diferenças entre os que não perdem o sentido de viver, baseados na espiritualidade ou noutros apoios, tendo assim mais possibilidade de lidar com a situação e aqueles que perdem o sentido existencial, ficando mais desarmados frente à adversidade. Há mesmo quem investigue a maneira de avaliar a presença e/ou a busca de significado para a vida, construindo para tal um questionário que mostrou possuir boas qualidade psicométricas (Steger et al. 2006).

Seja como seja, impõe-se re-humanizar a psicologia, buscar uma "psicologia da altura" (Frankl, 2001, p. 122) e ainda uma psicoterapia que promova a "vontade de significado" para que ela possa verdadeiramene servir o homem e ajudá-lo a singrar na vida, dar-Ihe um suplemento de alma, uma dimensão espiritual, possibilitando-Ihe voos mais elevados e não apenas intramundanos. Ora ninguém dá o que não tem, e a psicoterapia psicanalítica ou, no outro extremo, a comportamentista, pouco ou nada têm para dar em relação ao sentido da vida, do sofrimento e da morte. Numa época em que o homem vive a grande velocidade, porque pode andar de avião ou de carro, mas mais ainda porque pode navegar na Internet colocando-se, numa fracção de segundo, em contacto com o ponto mais distante da Terra, na realidade está estagnado psíquica e espiritualmente, vive aborrecido, deprimido.

A teoria e a prática logoterapêutica de Frankl, aqui apenas esboçada, poderia aproximar-se de outros autores provindos da filosofia (existencialista), da psicologia humanista e ainda dos neo-psicanalistas que procuraram aplicar a psicanálise à sociedade actual, como é o caso de Erich Fromm que de qualquer forma se aproveitou dos conhecimentos freudianos, tentando alargar os horizontes da psicanálise e dando-Ihe uma perspectiva histórico-sociológica de influência marxista mas também aberta a outras visões. Fromm pensa que o homem deve perder o "medo à liberdade" (1971) frente a si mesmo e à sociedade, abrindo-se principalmente ao amor, aprendendo a "arte de amar" (1972) e conjugando o verbo 'amar' em todos os tempos e modos, pois o "coração do homem" (1972) está feito para amar e não para se autodestruir e destruir os outros e a natureza. Outro exemplo 
vem de Karen Horney, também ela uma neo-psicanalista que, entre outros livros, escreveu um com um título bem sugestivo - "A personalidade neurótica do nosso tempo" (cf. Barros, 2007).

\section{Referências bibliográficas}

Antunes, C. (2005). As inteligências múltiplas e os seus estímulos. Porto: ASA.

Barros, J. (2004). Psicologia Positiva. Porto: ASA.

Barros, J. (2006). Espiritualidade, sabedoria e sentido da vida nos idosos. Psychologica, 42, 133-145.

Barros, J. (2007). Neuróticos num mundo neurótico. Porto: LivPsic.

Brito, J. H. (2009). O desafio da esperança: para uma visão antropológica. Brotéria, 168 (2), 155-164.

Brody, C. (1999). Existential issues of hope and meaning in late life therapy. In M. Duffy (Ed.), Handbook of Counseling and Psychotherapy with older adults (pp. 91-106). New York: John Wiley \& Sons.

Carlisle, C. (2000). The search for meaning in HIV and AIDS: The carers' experience. Qualitative Health Research, 10 (6), 750-765.

Ersek, M. e Ferrell, B. (1994). Providing relief from cancer by assisting in the search for meaning. Journal of Palliative Care, 10 (4), 15-22.

Frankl, V. (1998). Senso e valori per l'esistenza (la risposta della logoterapia) ( $2^{\mathrm{a}} \mathrm{ed}$ ) Roma: Città Nuova (original inglês de 1969 - The will to meaning).

Frankl, V. (1999). El hombre en busca de sentido (20 ed.). Barcelona: Herder.

Frankl, V. (2001). Alla ricerca de um significato della vita (6 $6^{\mathrm{a}}$ reimp.). Milano: Nurcia (original em alemão de 1952).

Fromm, E. (1971). El miedo a la libertad. Buenos Aires: Ed. Paidos.(The fear of freedom).

Fromm, E. (1972). El arte de amar. Buenos Aires: Ed. Paidos (The art of loving).

Fromm, E. (1972). El corazon del hombre. México: Fundo de Cultura Economica The heart of man, 1964).

Gardner, H. (1999). Are there additional intelligence? The case for naturalist, spiritual, and existential intelligences. In J. Kane (Ed.), Education, Information, and Transformation (pp.111-131). Upper Saddle River, NJ: Prentice Hall.

Jim, H., Richardson, S., Golden-Kreuz, D., Andersen, B. (2006). Strategies used in coping with a cancer diagnosis predict meaning in life for survivors. Health Psychology, 25 (6), 753-761.

Jung, C. (1933). Modern man in search of a soul. New York: Harcourt.

Kant, E. 1966). Logique. Paris: Vrin.

Lipovetsky, G. (1988). A era do vazio: Ensaio sobre o individualismo contemporâneo. Lisboa: Relógio d'Água.

Lipovetsky, G. (1989). O império do efémero: A moda e o seu destino nas sociedades modernas. Lisboa: Dom Quixote.

Maddi, S. (1967). The existencial neurosis. Journal of Abnormal Psychology, 72, 311-325.

Newcomb, M. (1986). Nuclear attitudes and reactions: Associations with depression, drug use, and quality of life. Journal of Personality and Social Psychology, 50, 906-920.

O’Neill, B. (2001). Psychotherapy and our search for meaning. Gestalt, 5 (3). 
Reker, G. e Wong, P. (1988). Aging as an individual process: Toward a theory of personal meaning. In J. Birren e V. Benston (Eds), Emergent Theories of Aging (pp. 214-246). New York: Springer.

Rojas, E. (1988), O homem light - Uma vida sem valores. Gráfica de Coimbra.

Schulenberg, S., Hutzell, R., Nassif, C. e Rogina, J. (2008). Logotherapy for clinical practice. Psychotherapy: Theory, Research, Practice, Training, 45 (4), 447-463.

Seifert; L. (2002). Toward a psychology of religion, spirituality, meaning-search, and aging.: Past research and a practical application. Journal of Adult Development, 9 (1), 61-70.

Steger, M., Frazier, P., Oishi, S., Kaler, M. (2006). The meaning in life questionnaire: Assessing the presence of and search for meaning in life. Journal of Counseling Psychology, 53 (1), 80-93.

Yalom, I. (1980). Existencial Psychotherapy. New York: Basic Books.

Terra, D. (2009). A busca do sentido da vida. Brotéria, 168 (2), 137-154.

Zica, S. e Chamberlain, K. (1987). Relation of hassles and personality to subjective well-being. Journal of Personality and Social Psychology, 53, 155-162.

Zica, S. e Chamberlain, K. (1992). On the relation between meaning in life and psychological well-being. British Journal of Psychology, 83, 133-145.

\section{Search and cure of meaning for life}

The search for meaning in life, or life with meaning, is today as much or even more urgent than in the time of V. Frankl, who specifically studied this topic or psycho-spiritual dimension. The author perceives the lack of existential meaning, but searches for an appropriate therapy- logotherapy. After a brief introduction, the desire for meaning proper to a rational being is studied, and after that the attempt to cure the lack of meaning, that somehow makes psychology, and in particular psychotherapy, more human.

KEY-WORDS: search for meaning; desire for meaning; logotherapy; psychology.

\section{Recherche et cure de sens de la vie}

La recherche de sens de la vie, ou de la vie avec sens, est aujourd'hui plus urgente qu'a l'époque de V. Frankl qui a étudié ce topique ou cette dimension psychologique. L'auteur constate non seulement le manque de sens existentiel, mais il cherche aussi une thérapie adéquate - la logothérapie. Après une brève introduction, on étudie la volonté de sens qui est propre à l'homme rationnel, puis la tentative de cure du manque de sens, qui d'une certaine façon rend la psychologie, et particulièrement la psychothérapie, plus 'humaine'.

MOTS-CLÉS: Recherche de sens; volonté de sens; logothérapie; psychologie. 